\title{
AS VIAGENS DE RETORNO DE ULISSES E LEOPOLD BLOOM
}

\section{Roberto Carlos Ribeiro ${ }^{1}$}

Resumo: Este paper apresenta uma leitura de duas obras estrangeiras, Ulisses, de James Joyce, e Odisséia, de Homero, procurando analisar os percursos das personagens principais através de seus deslocamentos. A viagem no espaço geográfico de Ulisses e a viagem vertical na memória de Leopold Bloom. Tal percurso demonstrará a relação das personagens com os seus mundos e consigo mesmas, denotando a trajetória da desagregação do homem, desde o mundo grego até a contemporaneidade.

Palavras-chave: Viagem, Literatura moderna, Deslocamento, Memória.

Abstract: This paper presents a reading of two foreign works, Ulysses, by James Joyce, and Homer's Odyssey, seeking to analyse the wanderings of the principal characters through the forms of their displacement: Ulysses' voyage through geographic space, and the vertical trip through memory of Leopold Bloom. In such a way, the relation of the characters with their worlds and with themselves will be demonstrated, and the trajectory of man's disaggregation, from the Greek world to contemporary times.

Key words: Trip, Modern literature, Displacement, Memory.

Ulisses viajante é uma das imagens mais recorrentes na literatura mundial. Fala-se de viagem, lembra-se da Odisséia, obra escrita por Homero no séc. VI a.C. De uma pessoa que tenha que lutar muito para obter algo desejado, diz-se que enfrentou uma odisséia para conseguir seu intento. O cineasta americano Stanley Kubrick (1928-1999) empreendeu contar a história da racionalidade humana no filme "2001, uma odisséia no espaço", desde os símios até a IA (inteligência artificial) como uma verdadeira odisséia espacial. Ler Ulisses (1922), de James Augustine Aloysius Joyce (1882-1941), é uma odisséia. O termo odisséia, portanto, passou a ser sinônimo de tarefa árdua, que exige força quase sobrenatural, mas ao mesmo tempo deixa o gosto da missão cumprida, que deu trabalho, e também prazer; tanto pela realização em si quanto pela constatação de poder de superação da vontade humana.

Invocando-se as musas da compreensão, da calma, do esforço, do entendimento e da alegria, empreende-se atravessar o mar da literatura, às vezes de águas calmas e claras, às vezes turbulentas e escuras, carregando no bojo dessa nau capitânia duas obras assombrosas e assustadoras, conforme visualizavam, no destino, os navegantes de priscas eras: Odisséia, de Homero (1981), e Ulisses, de James Joyce (2005). A viagem será o enfoque desse ensaio. E para tanto se faz necessário, de

1 Mestre e doutorando em Teoria da Literatura pela Pontifícia Universidade Católica do Rio Grande do Sul - PUC/RS. Endereço eletrônico: robertocarlosribeiro@bol.com.br. 
antemão, caracterizar alguns conceitos. Como se disse, acima, que o termo odisséia está relacionado a se fazer algo que dá trabalho, fica subentendido que tal necessidade se faz presente a um deslocamento que demanda tempo e/ou espaço (geográfico), não necessariamente nessa ordem. O deslocamento relacionado à odisséia subentende, também, o esforço empregado para se obter o objetivo proposto.

O primeiro conceito de viagem seria o deslocamento de um ponto A para um ponto $\mathrm{B}$, em um sentido horizontal. Um terceiro ponto pode aparecer. Regina Zilberman destaca a verticalização da narrativa:

viagens significam deslocamento no espaço, e sua visualização mais simples e usual é resumida pela linha horizontal. Mas podem tomar configuração vertical: Ulisses desce aos infernos, Gilgamesh, ao fundo do mar. Na História verdadeira, em que Luciano, no século II, parodia a Odisséia, de Homero, e os Argonautas, de Apolônio de Rodes, contam-se episódios ocorridos na Lua e nos Campos Elíseos, num permanente desafio à força da gravidade e às possibilidades de trânsito entre o alto e o baixo (2003, p. 119).

Ou seja, uma narrativa de viagem pode ser proposta como uma bidimensionalidade espacial. Mais ainda, pode-se criar um quarto ponto de expansão para a viagem.

Nada impede que, ao deslocamento no espaço, se junte um deslocamento de memória, portanto, interior. A chamada viagem vertical transfere o espaço geográfico para o espaço da memória e é ali que a viagem também pode acontecer. Essa é a teoria de Wladimir Krysinski. Para ele: "é particularmente significativo ver que na modernidade que conduz de Cervantes a Canetti, Michaux ou Le Clézio por exemplo, a viagem verticaliza-se de alguma maneira, e o espaço transforma-se noologicamente por interiorização e por mythopoesis" (2003, p. 24). Tem-se, no presente ensaio, as duas vertentes das narrativas de viagens: a personagem Ulisses, de Homero, que faz uma viagem predominantemente horizontal e Leopold Bloom, de James Joyce, uma viagem que tende para o memorial.

Ulisses, na Odisséia, percorre o espaço geográfico das ilhas e do mar gregos, durante dez anos, na tentativa de voltar para casa, Ítaca. Há, portanto, um deslocamento explícito de tempo e espaço-geográfico. Leopold Bloom percorre o espaço geográfico de Dublin, na Irlanda, durante vinte e quatro horas, o internacionalmente conhecido Bloomsday, 16 de junho, até chegar em casa. Há, aqui, um deslocamento explícito do tempo e espaço-pseudo-geográfico, já que o trânsito de Leopold Bloom pelas ruas de Dublin é muito pouco para se constituir uma "viagem". Apesar de Xavier de Maistre ter feito uma Viagem à roda de meu [seu] quarto. Ocorre aqui a verticalização da viagem. O espaço-geográfico míngua para dar lugar ao espaço da memória, à viagem vertical, em que as lembranças e os questionamentos do ser passam a substituir o espaço-geográfico como deslocamento. 
Sorrateiramente, a memória torna-se a mola propulsora tanto do relato de viagem espaço-temporal como do relato de viagem memo-temporal. Uma observação se faz necessária, quando se diz "relato de viagem" pensa-se na narrativa de alguém que explora algum espaço e considera-se tal obra como não-ficção, por exemplo: a carta de Caminha ou Roteiro da primeira viagem de V asco da Gama, de Álvaro Velho, ou O turista aprendiz, de Mário de Andrade ou Guias práticos, históricos e sentimentais de cidade brasileira, de Gilberto Freire, e tantos outros, como se nessas narrativas não houvesse ficção, mas sim a pura realidade e verdade. Ledo engano, todas as narrativas têm o seu "quê" ficcional, até as biografias e autobiografias. Mas essa relação real-ficção não será discutida aqui, visto que as duas obras em apreço são textos academicamente designados por ficcionais.

O relato de Ulisses sobre as peripécias de sua viagem traz a recorrência da memória, visto que o mesmo não se faz no exato momento da ocorrência. O binômio deslocamento e memória é irredutível. Recorrer à memória traz o perigo da inverdade da aventura. É assim que Ítalo Calvino vê a questão com relação a Ulisses, quando se pergunta "quantas Odisséias contém a Odisséia?". Qual dos relatos contidos no livro é o verdadeiro? O relato de Ulisses aos feacos? O relato de Ulisses a Eumeu? O relato de Ulisses à Penélope?

O relato que o irreconhecível Ulisses faz ao pastor Eumeu, depois ao rival Antinous e à própria Penélope é uma outra Odisséia, completamente diversa; as peregrinações que levaram de Creta até ali a personagem fictícia que ele afirma ser, uma história de naufrágios e piratas muito mais verossímil do que aquela que ele mesmo fizera ao rei dos feacos. Quem nos garante que não seja esta a "verdadeira" Odisséia? Mas esta nova Odisséia remete a uma outra Odisséia ainda: o cretense encontrara Ulisses em suas viagens; assim, eis que Ulisses narra de um Ulisses em viagem por países em que a Odisséia considerada "verdadeira" não o fizera passar (CALVINO, 1993, p. 21).

Quem poderia dizer qual dos relatos na Odisséia seria o que, realmente, foi feito por Ulisses? Tem-se, somente, a palavra e a memória dele, portanto todos eles podem ter um pouco de verdade e um pouco de mentira. As várias versões da história contadas por Ulisses, dentro da obra Odisséia, declaram a mobilidade dos senhores detentores do poder patriarcal da sociedade, contrapondo-se à imobilidade, tanto da mulher Penélope quanto dos servidores. Não importa se verdadeiro ou falso, o relato da viagem desmascara a mobilidade de uma classe.

A essência da Odisséia pode ser a demonstração do quadro dos que ficam, Penélope, os pretendentes e os serviçais e o quadro dos que partem e/ou locomovem-se, os guerreiros e Ulisses. Por esse ângulo, Telêmaco é observado no exato momento em que ocorre a transformação de ser estático em ser movente. O filho de Ulisses, ciente de suas responsabilidades, sai da casa paterna e do seu estado de mobilidade para ir ao encontro do destino de seu pai e do seu, navegando, percor- 
rendo terras e se socializando com outros guerreiros e velhos, numa espécie de iniciação social, como um rito de passagem. Já Penélope, enquanto governante de sua casa, é quase que uma observadora do mundo mecânico das ritualidades domésticas e sociais. Telêmaco adolescente dá ordens à sua mãe, reforçando a questão da masculinidade como força de direção. Penélope teima em se manter esposa de Ulisses, mesmo sem ter certeza de que este esteja vivo. Usa de artimanhas para tentar retardar as investidas dos pretendentes, mas ao mesmo tempo, sabe que não terá forças pessoais e nem sociais para conter essas pretensões. A construção da mulher fiel acaba corroborando para a imobilização da imagem da família, em que a mulher, igualmente como a propriedade, reforça a estabilização para a qual tende a viagem de Ulisses.

Às peripécias e aventuras de Ulisses: a vida amorosa com Calipso, a luta com o Ciclope, os naufrágios, a descida aos infernos, a luta contra Caribde e Cila, contrapõe-se o mundo estático em Ítaca, como se a família de Ulisses, em motocontínuo, sustentasse a si própria com um mínimo de cuidado:

Chega-se à consciência de que a vida, nos poemas homéricos, só se desenvolve na classe senhorial - tudo o que porventura viva além dela só participa de modo serviçal. A classe senhorial é ainda tão patriarcal, tão familiarizada com as atividades quotidianas da vida econômica, que às vezes se chega a esquecer seu caráter de classe. Só que ainda é inconfundivelmente uma espécie de aristocracia feudal, cujos homens dividem a vida entre a luta, a caça, as deliberações no mercado e os festins, enquanto as mulheres vigiam as criadas em casa (AUERBACH, 2004, p. 18).

O paroxismo entre imóvel e móvel permanecerá na obra, já que Ulisses não pretende estabelecer-se em casa. A sua missão é, depois de resolvida a questão dos pretendentes, continuar a viagem, como prediz Tirésias:

mas, logo que, em teu palácio, tenhas matado os pretendentes, ou ardilosamente ou às claras, à ponta do bronze, toma um remo bem trabalhado e parte, até chegares à terra de uns homens que nunca viram o mar e comem os alimentos sem sal; não conhecem, portanto, as embarcações de flancos vermelhos nem os remos polidos que são as asas dos navios (HOMERO, 1981, p. 103).

Tal continuação da viagem é necessária para que Ulisses pague o devido tributo ao deus Posídon - deus dos mares - e só depois possa voltar para casa e esperar uma morte tranqüila ao lado de Penélope:

Quando encontrares outro viajante, e este te disser que levas sobre teu robusto ombro uma pá de joeirar grão, então crava no solo teu remo polido e oferece um belo sacrifício ao soberano Posídon, um carneiro, um touro, um varrasco; volta, em seguida, a casa e sacrifica hecatombes sagradas aos deuses imortais (HOMERO, 1981, p. 103). 
Ítaca e Penélope são portos em que o viajante pode, de vez em quando, atracar a sua nau para refazer-se, com vistas para uma nova aventura.

Vinte e cinco séculos depois, Ulisses retorna pelas mãos de um irlandês, que escreve em francês, unindo termos em alemão e italiano. O Ulisses moderno está centrado na personagem Leopold Bloom. Quando do lançamento de Ulisses, em 1922, vários críticos não conseguiram entender o título da obra e foi preciso que Joyce, através das indicações e roteiros dados ao crítico Stuart Gilbert, em 1930, praticamente abrisse caminho para o entendimento de sua obra. As aventuras e peripécias enfrentadas por Ulisses são transferidas para Bloom, dentro de um contexto muito próprio e desfigurado da viagem da personagem grega. Assim como Telêmaco tem o seu espaço na Odisséia, aqui também Stephen Dedalus corporificará essa personagem. O terceiro lado do triângulo das personagens gregas será composto por Molly, a Penélope às avessas de Joyce.

A viagem de Leopold Bloom, jornada no cotidiano de uma vida comum e banal, aponta para a desmaterialização do porto seguro dos itens clássicos da base social: família (esposa e filhos) e o trabalho. Tudo aquilo que poderia dar apoio a sua existência desmancha-se em incertezas. No âmbito particular, a dúvida sobre a fidelidade da esposa, as lembranças da perda precoce do filho Rudy, do suicídio de seu pai, a preocupação com a filha adolescente Milly. No espectro público, Bloom tem que suportar a irracionalidade nacionalista dos seus companheiros. Leopold Bloom, um senhor banal e algo cômico, de origem judaica, tem um dia banal em sua vida banal. Das oito horas da manhã às duas da madrugada do dia seguinte, Bloom viaja as suas dezoito horas de cotidianidade.

Stephen Dedalus há tempos faz a sua viagem iniciada em Retrato do artista quando jovem (1916). A sua preocupação com a arte continua a sua saga. Em Ulisses, o jovem meio perdido socialmente, sem casa, sem família constituída, espelhandose em Leopold como a figura paterna, anda buscando a essência da arte na vida. Depois de tentar sair de seu lugar de origem, viajando para Londres, é obrigado a retornar por causa da doença de sua mãe. Faz um ano já que Stephen está de volta a Dublin. Com a morte de sua mãe, a família acaba por se desintegrar. Enquanto os irmãos de Stephen não têm o que comer, o pai anda pelos bares bebericando. $\mathrm{O}$ jovem se considera uma espécie de órfão e, conscientemente ou não, procura um pai. Stephen não tem para onde voltar. Deixou a Torre Martelo, rejeita a acolhida de Leopold Bloom. Antes, havia abandonado a casa de seu pai: "a visão mental de Stephen estando por demais ativamente ocupada em retratar novamente a lareira de sua casa a última vez em que a viu com sua irmã Dilly" (JOYCE, 2005, p. 642). A técnica do ensaio reforça a fala de Dedalus quando tenta provar a sua tese sobre Hamlet e a questão da paternidade em Shakespeare.

Molly Bloom, responsável pelo famoso monólogo interior, último episódio do livro, refaz, por sua vez, através da memória, a viagem de encontro a si e ao 
marido, Leopold Bloom. Enquanto ele adormece, ela desperta. Essa cantora, apresentada como uma mulher fogosa, mostra a sua luxuriante personalidade através de imagens como a da leitura de Paul de Kock, pela leitura de outro livro que não lhe satisfez: "não há nada de obsceno nele. Ela está apaixonada pelo primeiro camarada o tempo todo?" (JOYCE, 2005, p. 74); pelas peças do vestuário esparramadas pelo quarto; pela citação irônica e bem humorada do mundo grego através do termo "metempsicose" e pela referência ao mundo homérico gravado no urinol: "o livro, esparramado de encontro à protuberância do urinol com decoração grega homérica” (JOYCE, 2005, p. 74).

Não é por acaso que Stephen e Bloom encontram, à noite, fim da jornada do dia, o marinheiro D.B. Murphy que sonha com sua terra e sua esposa, a esperálo:

É isso mesmo - disse o marinheiro - Forte Camden e Forte Carlisle. É de lá que eu provenho. Eu pertenço àquele lugar. É de lá que eu provenho. Minha mulherzinha está lá. Ela está esperando por mim, eu sei. Pela Inglaterra, o lar e a belez̧a. Ela é minha própria e verdadeira mulher que eu não vejo há sete anos, navegando por aí (JOYCE, 2005, p. 646).

A sina dos marinheiros, de ficarem longe de suas terras e de sua família, retrata o ambiente vivido pelas duas personagens. Stephen está longe da família, pátria e da relação com a arte realizada em Dublin, quiçá no mundo. Bloom está com problemas no seu relacionamento com Molly. Ambos não são marinheiros, mas carregam o estigma da classe.

Leopold corrobora o deslocamento interior como uma forma de se viajar e de se aventurar, mesmo quando não se faz a viagem no espaço geográfico. O desejo de tal percurso acaba se refletindo na mente da personagem: "Ihe lembrava de certa maneira um plano por muito tempo acariciado de viajar para Londres via alto-mar para não dizer que não tivesse jamais viajado extensivamente por alguma grande extensão mas de coração ele era um aventureiro nato" (JOYCE, 2005, p. 648).

Tais acontecimentos descortinam o mundo moderno individualizado. Se Ulisses pode ser a representação da coletividade, Bloom e seus companheiros retratam a crescente individualidade do mundo contemporâneo, conseqüência do conhecimento incompleto dos atos humanos. É dessa forma que Cheryl Herr percebe a obra de Joyce:

Tentei [...] estabelecer o sentido em que Ulysses finge revelar identidades, mas de fato solapa nosso conceito tradicional da mente ao derivar, da forma mais clara, o conteúdo da consciência de textos e convenções existentes. Como apresentado em Ulysses, os indivíduos concebem a verdade de seus eus alicerçada na cultura circundante, mas num inconsciente pessoal inespecificável e extremamente ina- 
cessível. Todavia, o discurso derivado de Ulysses cria um senso diferente do que é ser uma pessoa no mundo de Joyce: vive-se num fluxo de consciência que afinal não se distingue de outros fluxos discursivos; nunca se pode conhecer de todo os imperativos externos que modelam o desejo e condicionam a ação. No romance, pois, os significantes da natureza e da individualidade são indistinguíveis dos da cultura e da convenção (HERR, 1992, p. 200).

O real e o imaginário, assim como o vivido e o pensado, são as pontas das viagens feitas pelas personagens através de seus inconscientes, num vértice veloz à procura de identidades que possam dar um porto às personagens cansadas pelas lutas diárias. Não se pode deixar de perceber, nesse constante esforço de identificação, a relação com as identidades fluidas da modernidade como signo do homem contemporâneo. Esse é o mundo de Bloom, o Ulisses moderno.

\section{As Viagens: UlisSES NA Rota de HARMONIZAÇÃo E LEOPOLD BLOOM NA ROTA DE COLISÃo}

O mundo na literatura se abre como a quilha do navio; arrasta e desobstrui o caminho pelo mar. No mundo grego de Ulisses, o "mundo fechado" (cf. LUKACS, 2000) mantém a organização e comunica a despreocupação da personagem com relação à constituição familiar e social. Ali o perigo são as invejas e os ciúmes dos deuses, não os dos homens. Para Ulisses, é fácil lutar e vencer os pretendentes à mão de Penélope, mas impossível, sem ajuda de outros deuses, enfrentar a fúria de Posídon. Sem as informações de Circe e sem as profecias de Tirésias no Hades, o herói grego não conseguiria voltar para casa. Ítaca é apenas um ponto no mapa, mas é o espaço do regresso, o lugar da harmonia, abalado a princípio pelas intromissões estrangeiras dos pretendentes, mas com grande possibilidade de obter a tranqüilidade e a conciliação. Ulisses navega em direção à harmonia. O seu mundo, contemplando esposa, filho e propriedade com escravos, apesar da iminente destruição, permanece intacto à sua espera e dá sinais de que assim continuará.

No mundo contemporâneo de Leopold Bloom, o homem está só. Desamparadas pelos deuses e céticas quanto à espiritualidade, as personagens do romance vagam pelas ruas à procura de um marco de identidade pessoal que justifique a existência. A família já não tem o mesmo significado de antes, de núcleo aglutinador de base. Para elas não existe solução. $\mathrm{O}$ ciclo da jornada do dia se perpetua. $\mathrm{O}$ casal sem o filho em casa, sempre vindo e indo embora, refletindo o eterno retorno da cotidianidade e da banalidade. Ulisses é também um eterno tecer e destecer histórias, personagens, narrativas. Por isso tudo, Leopold Bloom navega em direção à desarmonia. O seu mundo, contemplando esposa e filhos, vive em constante desestruturação. 
Homero na antiguidade, Dante na Idade Média, Shakespeare no Renascimento e Joyce na modernidade. Geralmente, essa é a linha canônica traçada quando se quer fazer uma viagem horizontal pelas obras eleitas pelos simples mortais como aquelas que formaram e informaram a inteligência do homem e sua cultura. No percurso vislumbrado de um mundo fechado em sua cultura, em que o material (homem) e o imaterial (deuses) conviviam em um ambiente perfeito, segundo George Lukacs, para um mundo em completa ruína, em que os valores perderam a razão de ser e o homem se descobriu como "mais um" no mundo e não "o único", é inegável que Ulisses, de Joyce, retrataria o homem perdido na sua pequenez e banalidade cotidiana.

As duas mais manifestas viagens clonadas nas literaturas mundiais, a viagem horizontal de Ulisses e a viagem essencialmente vertical de Dante, do inferno para o céu, na Divina Comédia, traçaram a rota dos percalços materiais e espirituais que afligiram, afligem e afligirão o homem em sua busca cotidiana, seja do lar e do amor, seja da chave enigmática que poderá reordenar todas os sentidos no mundo desestruturado das personagens contemporâneas. Leopold Bloom é o anti-herói moderno, perdido, fendido em dois, conforme a tese de Sigmund Freud (1972), que crê que exista, na humanidade, uma predisposição à existência de um aparelho pulsional especificamente humano, além do mero instinto, que condena o homem à falta, ao inacabamento, à frustração socialmente necessária. $\mathrm{O}$ homem não pode mais ser total, pois é ambíguo em sua própria essência. Tal preocupação não aflige Ulisses, criado para ser honrado nas guerras e nas realizações de saques milionários pelas terras em que passa. Sua única preocupação é poder voltar para a sua terra, já que a ninfa Calipso não mais lhe agradava. Bloom volta para casa, mas continua desabrigado na sua concretude. Ulisses retorna à casa pleno de responsabilidade $\mathrm{e}$ de reconhecimento. Ambos fazem a viagem da volta, mas como são diferentes os portos... 


\section{REFERÊNCIAS}

AUERBACH, Erich. Mimesis: a representação da realidade na literatura ocidental. Vários tradutores. 5 ed. São Paulo: Perspectiva, 2004.

FREUD, Sigmund. Obras completas. Madrid: Nueva, 1972.

HERR, Cheryl. Arte, vida, natureza e cultura, Ulysses. In: NESTROVSKI, Arthur. (Org.). Riverrun: ensaios sobre James Joyce. Trad. Jorge Wanderley; Lya Luft; Marco Luchesi. Rio de Janeiro: Imago, 1992.

HOMERO. Odisséia. Narrativa. Trad. Antônio Pinto de Carvalho. São Paulo: Abril Cultural, 1981.

JOYCE, James. Ulisses. Trad. Bernardina da Silveira Pinheiro. Rio de Janeiro: Objetiva, 2005.

LUCAKS, George. A teoria do romance. São Paulo: Duas Cidades; Ed. 34, 2000.

KRYSINSKI, Wladimir. Discurso de viagem e senso de alteridade. Organon, Revista do Instituto de Letras da Universidade Federal do Rio Grande do Sul, Porto Alegre, n. 34, v. 17, 2003.

ZILBERMAN, Regina. Brás Cubas viajante. Organon, Revista do Instituto de Letras da Universidade Federal do Rio Grande do Sul, Porto Alegre, n. 34, v. 17, 2003. 
